\title{
EFFECTS OF CHRONIC HYPERCAPNIA ON ELECTROLYTE AND ACID-BASE EQUILIBRIUM. II. RECOVERY, WITH SPE- CIAL REFERENCE TO THE INFLUENCE OF CHLORIDE INTAKE*
}

\author{
By WILLIAM B. SCHWARTZ, $\dagger$ RICHARD M. HAYS, $\ddagger$ ADOLF POLAK AND \\ GORDON D. HAYNIE §
}

(From the Department of Medicine, Tufts University School of Medicine, and the Pratt ClinicNew England Center Hospital, Boston, Mass.)

(Submitted for publication February 15, 1961 ; accepted March 13, 1961)

Previous studies in both the rat $(1,2)$ and the $\operatorname{dog}(3)$ have demonstrated that chronic respiratory acidosis induces profound alterations in electrolyte balance, but little is known concerning the changes that occur when the stimulus of hypercapnia is withdrawn. The present experiments were undertaken in order to define the process of recovery, and to determine how it is influenced by the availability of sodium and chloride in the diet. For this purpose, balance studies were carried out in dogs returned to room air after a long period of exposure to a high $\mathrm{CO}_{2}$ atmosphere.

\section{METHODS}

Ten balance studies were carried out in 10 healthy female mongrel dogs weighing between 13 and $20 \mathrm{~kg}$. The experimental procedure, analytical methods, and calculation of the balance data were the same as those described in the preceding paper (3). In order to study the influence of sodium and chloride intake, the animals were divided into three groups whose diet was identical except in the following respects : 1) 4 dogs received 50 to $70 \mathrm{mEq}$ of sodium and chloride daily (high-salt group); 2) 4 dogs received approximately $5 \mathrm{mEq}$ of sodium and 3 $\mathrm{mEq}$ of chloride daily (low-salt group); in 3 this diet was supplemented by 60 to 120 mmoles of sodium chloride daily in the latter part of the study period ; 3) 2 dogs received a diet identical with that of the low-salt group except that sufficient potassium chloride was added in lieu of potassium phosphate to raise the daily chloride intake to $13 \mathrm{mEq}$.

Seven of the animals were among those described in the preceding paper on adaptation to hypercapnia

* Supported in part by grants from the National Heart Institute (H-759 and HTS-5309), the American Heart Association and the Life Insurance Medical Research Fund.

$\dagger$ Established Investigator, American Heart Association. $\ddagger$ Public Health Research Fellow of the National Heart Institute.

§ Medical Foundation Research Fellow, The Medical Foundation of Metropolitan Boston, Inc.
(3). In addition, each group contained 1 dog that was studied for only a few days prior to removal from $\mathrm{CO}_{2}$. The length of exposure to $\mathrm{CO}_{2}$ in all $10 \mathrm{dogs}$ ranged from 6 to 15 days. The recovery period was begun by the abrupt replacement of the high $\mathrm{CO}_{2}$ atmosphere (11 to 13 per cent) by room air.

\section{RESULTS}

\section{A. Collective data}

The typical findings during recovery period for Dog $\mathrm{H}$ on a low sodium chloride intake are shown in Table $I$ and Figures 1 and 2 of the preceding paper (3). Data for a representative recovery study on a high-salt intake are shown in Table II and Figures 3 and 4 of the same paper. These studies are closely similar to the others in each group and will not be discussed individually.

The collective data to be presented in this section were obtained from Dogs $\mathrm{I}, \mathrm{J}, \mathrm{K}$ and $\mathrm{O}$ in the high-salt group and Dogs, F. B, H and $Q$ in the low-salt group. In one dog from each group no control data were available and, therefore, only observations on plasma composition are presented in the figures. However, the pattern of change in the urine was fully comparable with that to be described in the other dogs on the same diet. The results in the two dogs receiving a diet containing $3 \mathrm{mEq}$ of sodium and $13 \mathrm{mEq}$ of chloride daily are presented separately in Section B.

1. Acid-base balance. In Figure 1 are shown the changes in plasma bicarbonate concentration in the high- and low-salt groups. It is apparent, although the level of plasma bicarbonate in both groups was nearly the same at the end of the $\mathrm{CO}_{2}$ period, that there was a marked difference during recovery. The high-salt group, whose plasma levels ranged from 36.1 to $38.1 \mathrm{mEq}$ per $\mathrm{L}$ prior to removal from $\mathrm{CO}_{2}$, showed a fall of approxi- 
TABLE I

$\Delta$ Cumulative balances during recovery from chronic respiratory acidosis

\begin{tabular}{|c|c|c|c|c|c|c|c|c|c|}
\hline Group & Dog & Days & $\mathrm{Cl}$ & $\mathrm{Na}$ & $\mathrm{Cl}-\frac{\mathrm{Na}}{1.3}$ & $\mathrm{~K}$ & $\begin{array}{l}\mathrm{K} \text { corr. } \\
\text { for } \mathrm{N}^{*}\end{array}$ & $\mathrm{~N}$ & $\begin{array}{c}\text { Cumula- } \\
\text { tive } \Delta \\
\text { net acid } \\
\text { excretion } \dagger\end{array}$ \\
\hline & & & \multicolumn{2}{|c|}{$m E q$} & \multicolumn{2}{|c|}{$m E q$} & $m E q$ & $g$ & $m E q$ \\
\hline & $\begin{array}{l}\mathrm{K} \\
\mathrm{I} \\
\mathrm{J}\end{array}$ & $\begin{array}{l}7 \\
7 \\
7\end{array}$ & $\begin{array}{r}+72 \\
+\quad 90 \\
+\quad 84\end{array}$ & $\begin{array}{l}+25 \\
+15 \\
+41\end{array}$ & $\begin{array}{l}+53 \\
+79 \\
+53\end{array}$ & $\begin{array}{l}-11 \\
+15 \\
+19\end{array}$ & $\begin{array}{l}+1 \\
+30 \\
+23\end{array}$ & $\begin{array}{l}-5 \\
-5 \\
-1\end{array}$ & $\begin{array}{r}-102 \\
-\quad 36 \\
-\quad 44\end{array}$ \\
\hline Low $\mathrm{NaCl}$ intake & $\begin{array}{l}\mathrm{H} \\
\mathrm{B} \\
\mathrm{F}\end{array}$ & $\begin{array}{l}6 \\
5 \\
6\end{array}$ & $\begin{array}{l}+18 \\
+13 \\
+14\end{array}$ & $\begin{array}{l}+\quad 5 \\
\quad 10 \\
+10\end{array}$ & $\begin{array}{r}+14 \\
-5 \\
+6\end{array}$ & $\begin{array}{l}+26 \\
-16 \\
+30\end{array}$ & $\begin{array}{l}-3 \\
+31 \\
+39\end{array}$ & $\begin{array}{l}+10 \\
-18 \\
-\quad 3\end{array}$ & $\begin{array}{r}-34 \\
+141 \\
+\quad 52\end{array}$ \\
\hline Salt added & $\begin{array}{l}\mathrm{H} \\
\mathrm{B} \\
\mathrm{F}\end{array}$ & $\begin{array}{l}9 \\
9 \\
8\end{array}$ & $\begin{array}{l}+281 \\
+177 \\
+130\end{array}$ & $\begin{array}{l}+282 \\
+173 \\
+133\end{array}$ & $\begin{array}{l}+64 \\
+44 \\
+28\end{array}$ & $\begin{array}{r}+80 \\
+87 \\
+22\end{array}$ & $\begin{array}{r}-42 \\
+6 \\
-7\end{array}$ & $\begin{array}{r}+44 \\
+29 \\
+11\end{array}$ & $\begin{array}{r}-145 \\
+\quad 54 \\
+\quad 14\end{array}$ \\
\hline
\end{tabular}

* $2.7 \mathrm{mEq}$ potassium $/ \mathrm{g}$ nitrogen.

$\dagger$ This value is not a balance but represents the change in net acid excretion.
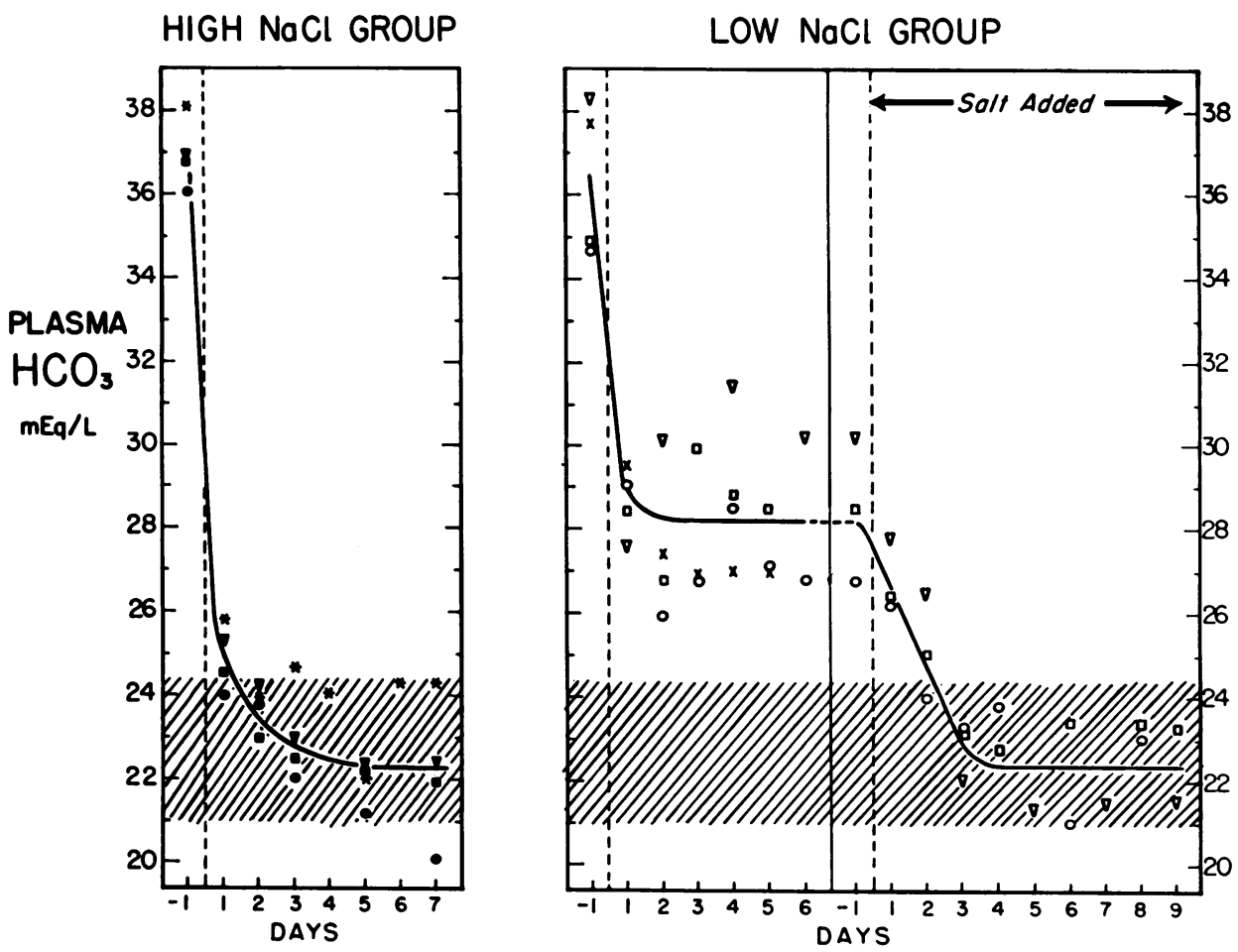

Fig. 1. Changes in plasma bicarbonate concentration during recovery from chronic RESPIRATORY ACIDOSIS. Day -1 , shown at the beginning of both the high- and low-salt studies, refers to the last day of exposure to $\mathrm{CO}_{2}$. Day -1 , shown prior to the addition of salt in the lowsalt group, refers to the last day of salt restriction. The shaded area gives the range of plasma bicarbonate concentration on the last day of the control period for all 8 dogs. The lines through the points were drawn by inspection. Note that only 3 of the 4 low-salt dogs were studied during salt supplementation. 

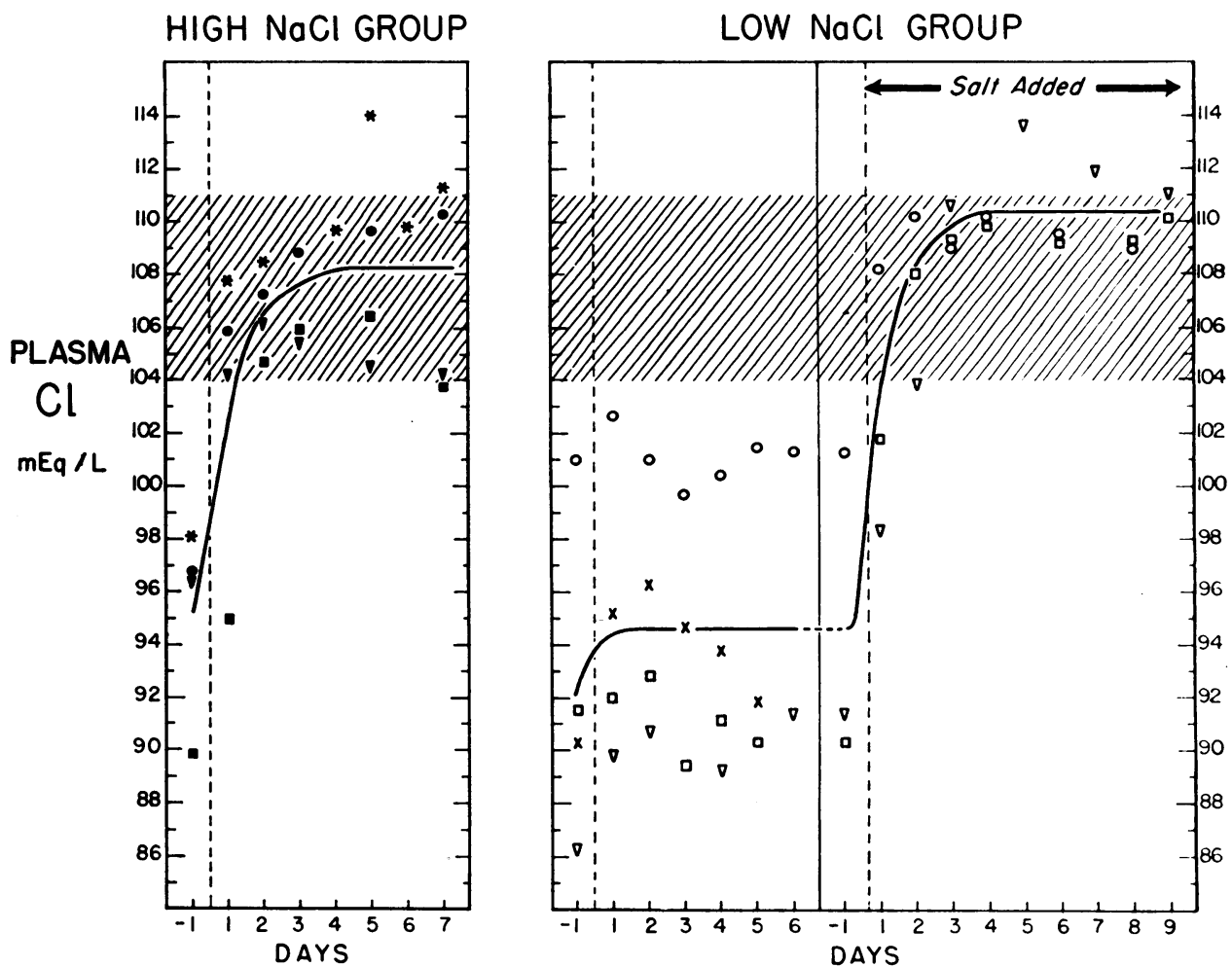

Fig. 2. Changes in plasma Chloride CONCENTRation during Recovery from Chronic RESPIRATORY ACIDOSIS. Day -1 , shown at the beginning of both the high- and low-salt studies, refers to the last day of exposure to $\mathrm{CO}_{2}$. Day -1 , shown prior to the addition of salt in the low-salt group, refers to the last day of salt restriction. The shaded area gives the range of plasma chloride concentration on the last day of the control period for all 8 dogs. The lines through the points were drawn by inspection. Note that only 3 of the 4 low-salt dogs were studied during salt supplementation.

mately $12 \mathrm{mEq}$ per $\mathrm{L}$ (range 24.0 to 25.8 ) at the end of 1 day in room air. Over the next several days there was a further fall to an average of approximately $22 \mathrm{mEq}$ per $\mathrm{L}$, which carried all animals into the range of plasma bicarbonate concentrations observed during the original control period. By contrast, the animals on a low-salt intake, whose plasma levels ranged from 34.7 to $38.3 \mathrm{mEq}$ per L, showed a smaller drop (average 8 ) during the first 24 hours in room air to plasma levels ranging from 27.6 to $29.5 \mathrm{mEq}$ per $\mathrm{L}$ and remained there. As seen in the right-hand portion of the figure, when the animals' diet was supplemented by sodium chloride there was a further fall of 5 to $6 \mathrm{mEq}$ in plasma bicarbonate concentration which restored the level to normal in each dog.

In Figure 3 are shown the values for plasma $\mathrm{pH}$ and $\mathrm{pCO}_{2}$ for the high- and low-salt groups.
Twenty-four hours after removal from the high $\mathrm{CO}_{2}$ atmosphere, the $\mathrm{pH}$ of all four high-salt dogs was slightly, but significantly, above the control range, averaging 7.44. During the next 3 days there was a progressive fall of $\mathrm{pH}$ to a normal range of 7.35 to 7.40 . Plasma $\mathrm{pCO}_{2}$ promptly fell to normal on the first day in room air, and remained normal subsequently. After 1 day in room air, $\mathrm{pH}$ was elevated to a range of 7.42 to 7.50 in three of the four low-salt dogs, but by contrast with the high-salt group, this slight elevation persisted. In the fourth low-salt dog plasma $\mathrm{pH}$ fell promptly to 7.39 and remained essentially unchanged. When salt was added to the diet of the low-salt group, $\mathrm{pH}$ fell to final values, ranging from 7.34 to 7.40 . Plasma $\mathrm{pCO}_{2}$ ranged between 37 and $50 \mathrm{~mm} \mathrm{Hg}$ prior to addition of salt and in one dog showed a questionable, slight fall after the salt supplementation. 
The changes in urinary net acid excretion, ammonia, titratable acid, and bicarbonate are shown for both the low-salt and high-salt groups in Figure 4. For each dog the value for the last 2 days (Days " -2 " and " -1 ") in $\mathrm{CO}_{2}$ are also shown. Net acid excretion in the high-salt dogs fell to values significantly below the control level on the first day in room air. By the second day net acid excretion in two animals had returned to control levels, where it remained for the rest of the study. In the third, it was depressed below control levels for 2 additional days but thereafter was in the control range. Of the three low-salt dogs, two showed little or no change in net acid excretion, either on the first or subsequent days after removal from $\mathrm{CO}_{2}$, with $\Delta$ net acid remaining at values slightly above control levels. In one, however, net acid excretion fell below control, where it remained for 2 days before returning to control levels. Cumulative $\Delta$ net acid excretion is shown for each dog in both the high- and low-salt groups in Table I.

Ammonium excretion, which was significantly elevated in the high-salt dogs on the last 2 days of exposure to $\mathrm{CO}_{2}$, fell to control levels on the first day in room air and remained in the control range for the rest of the study. The three low-salt dogs also showed a fall of ammonium excretion which carried two of them into the control range. Subsequently, ammonium excretion remained unchanged in all three. Titratable acid excretion, which during the last 2 days in $\mathrm{CO}_{2}$ was at or below control levels in both the high- and low-salt groups, remained in the same range on the first day in room air. Thereafter, it rose to control levels in the high-salt dogs and to slightly elevated levels in the low-salt dogs. Urinary bicarbonate excretion, which ranged from 2 to $11 \mathrm{mEq}$ per day during the last 2 days of the $\mathrm{CO}_{2}$ period in the high-salt dogs and from 1 to $6 \mathrm{mEq}$ per day in the low-salt dogs, showed no consistent change in either group on the first recovery day. ${ }^{1}$ In two dogs of each group, bicarbonate excretion on the first day was negligible and in all the dogs excre-

1 In 3 animals the urine passed during the first 8 to 12 hours in room air was analyzed separately and was found to contain nearly all of the bicarbonate excreted during the first recovery day.
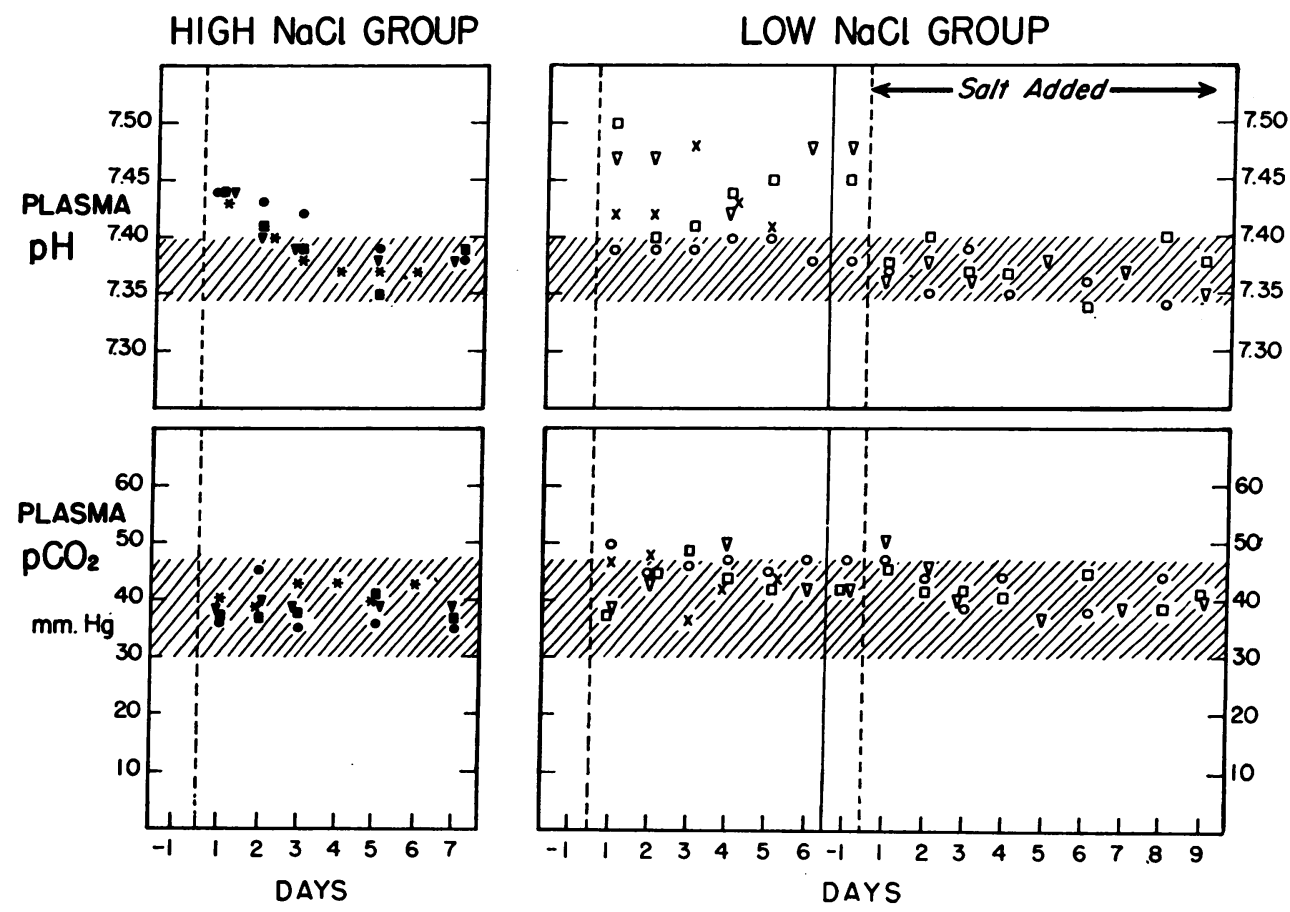

Fig. 3. Plasma PH AND PCO ${ }_{2}$ DURing ReCovery from Chronic RESPIRAtory acidosis. Day -1 , shown immediately prior to the addition of salt in the low-salt group, refers to the last day of salt restriction. The shaded areas give the ranges on the last day of the control period for all 8 dogs. Note that only 3 of the 4 low-salt dogs were studied during salt supplementation. 

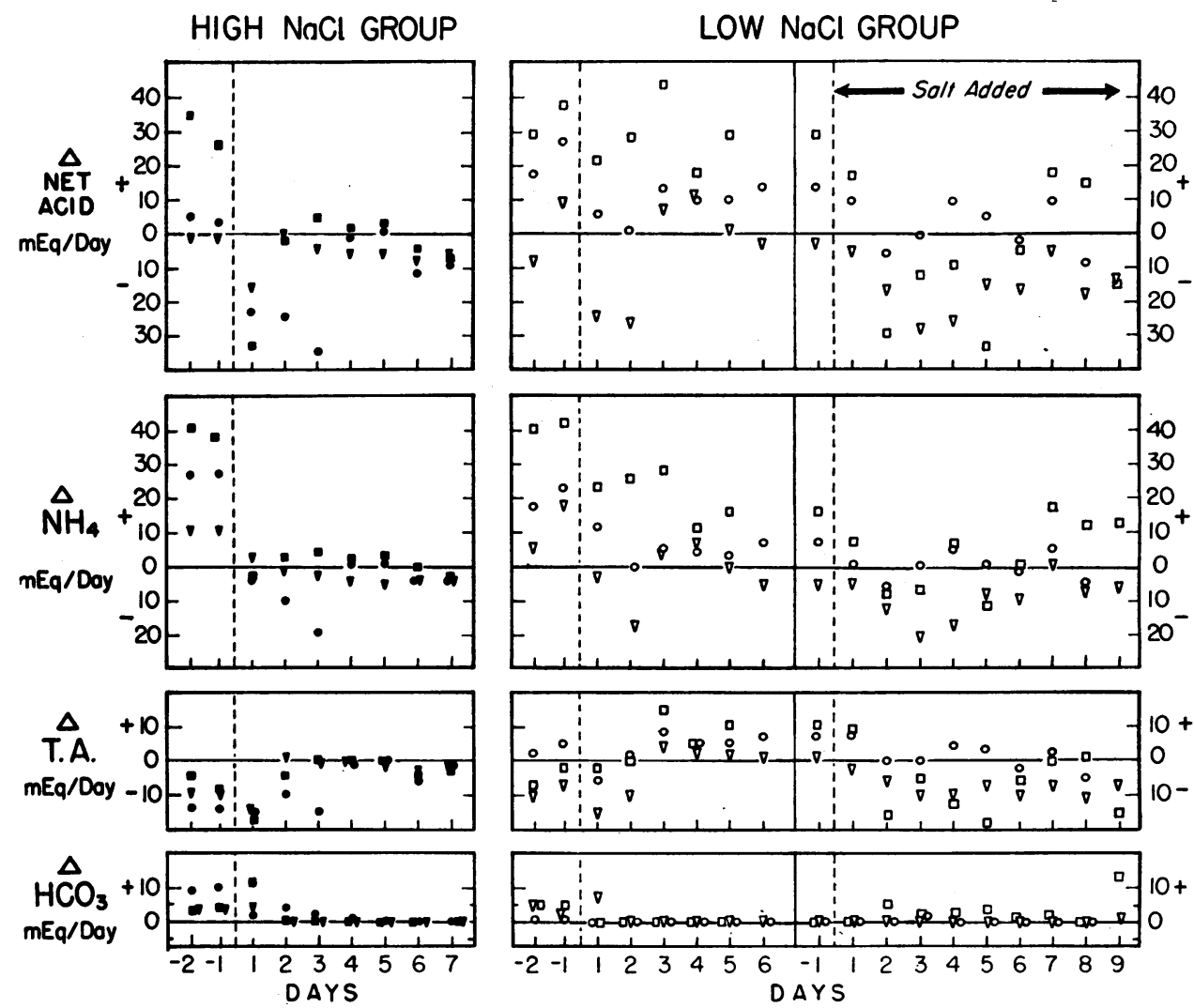

Fig. 4. Changes in Net acid, ammonium, titratable acid, and bicarbonate excretion DURING RECOVERY FROM CHRONIC RESPIRATORY ACIDOSIS. Days -1 and -2 , shown at the beginning of both the high- and low-salt studies, refer to the last 2 days of exposure to $\mathrm{CO}_{2}$. Day -1 , shown prior to the addition of salt in the low-salt group, refers to the last day of salt restriction. Each value represents the change from the mean daily excretion during the control period.

tion was at control levels (approximately $1 \mathrm{mEq}$ per day) on the second and subsequent days.

During the first day on which the low-salt dogs received extra salt, the plasma bicarbonate fell only slightly and there was little change in net acid excretion; however, during the next 2 days of salt supplementation, while plasma bicarbonate fell to the control levels, net acid excretion was diminished. After 1 or 2 further days of suppression, net acid excretion tended to return to control values. A pattern similar to that described for net acid excretion was followed both by ammonium and titratable acid. Bicarbonate excretion remained negligible during the period of salt supplementation. Cumulative $\Delta$ net acid excretion is shown for each dog in both the highand low-salt groups in Table I.

2. Chloride, sodium, and potassium. The plasma chloride concentration after removal of the high- and low-salt animals from the $\mathrm{CO}_{2}$ atmosphere is shown in Figure 2. In the high-salt group plasma chloride values for the last day in $\mathrm{CO}_{2}($ Day -1$)$ ranged from 90 to $98 \mathrm{mEq}$ per L. In room air there was a prompt rise in plasma chloride concentration to control levels of 104 to $111 \mathrm{mEq}$ per L. In the low-salt group the plasma chloride concentration on the last day in $\mathrm{CO}_{2}$ ranged from 86 to $101 \mathrm{mEq}$ per L, and on the first day in room air changed little (range 88 to 102). Over the next 5- to 6-day period plasma chloride concentration was essentially constant. After addition of sodium chloride to the diet, there was a prompt rise in plasma chloride concentration, which in 2 days carried the level to between 108 and $110 \mathrm{mEq}$ per $\mathrm{L}$, where it remained subsequently.

The changes in plasma chloride and plasma bicarbonate tended to be reciprocal, as they had been during the $\mathrm{CO}_{2}$ period (3), but after 1 day 
in room air, the fall in plasma bicarbonate regularly exceeded the rise in plasma chloride in both dietary groups. In the high-salt group, the discrepancy averaged $4 \mathrm{mEq}$ (range 3 to 7 ) and was attributable entirely to an increase in the level of "unmeasured anions." In the low-salt group it averaged $5 \mathrm{mEq}$ (range 3 to 7 ) and was due partly to a rise in unmeasured anions and partly to a fall in plasma sodium. During the next 4 to 5 days the discrepancy disappeared in the high-salt group; in the low-salt group it persisted until salt was added to the diet, at which time plasma chloride rose more (average $16 \mathrm{mEq}$ per $\mathrm{L}$ ) than plasma bicarbonate fell (average $6 \mathrm{mEq}$ per L).

Chloride excretion in the high-salt dogs, which during the latter part of the $\mathrm{CO}_{2}$ period had returned approximately to control levels, fell sharply during the first 1 or 2 days after removal from the high $\mathrm{CO}_{2}$ atmosphere. By the fourth day, chloride excretion in each animal had again returned to the control level, where it remained for the rest of the study. In the low-salt dogs the urine remained virtually chloride-free during the initial recovery phase. When the salt supplement was given, all the administered chloride was retained during the first day. In the course of the next 2 or 3 days there was a rise in urine chloride until approximate balance between intake and output was achieved.

In the three high-salt dogs a transient, modest retention of sodium occurred after removal from $\mathrm{CO}_{2}$, after which the output returned to control levels. In the low-salt dogs sodium excretion during the recovery phase closely paralleled the chloride excretion.

The cumulative $\Delta$ balance of chloride in the high-salt dogs during recovery is shown in Table I. It will be seen that in each dog it exceeded the cumulative $\Delta$ balance of sodium, which was small. The excess chloride calculated from the ratio of the concentrations of the two ions in extracellular fluid is also shown in Table I.

During salt supplementation all three low-salt dogs retained large quantities of sodium despite the fact that they had lost little or none during the $\mathrm{CO}_{2}$ period (3). Since these dogs had developed a sodium deficit during a control period on a lowsalt diet, such a retention would be anticipated, but the ratio of chloride to sodium retained was in all instances greater than would be required
TABLE II

$\Delta$ Cumulative potassium balance during chronic exposure to a high $\mathrm{CO}_{2}$ atmosphere

\begin{tabular}{|c|c|c|c|}
\hline & Dog & $\mathrm{K}$ & $\begin{array}{l}\mathrm{K} \text { corr } \\
\text { for } \mathrm{N}^{*}\end{array}$ \\
\hline $\mathrm{High} \mathrm{NaCl}$ intale & \multicolumn{3}{|c|}{$m E q$} \\
\hline & $\mathrm{J}_{\mathrm{J}}^{\mathrm{I}}$ & $\begin{array}{l}-52 \\
-18 \\
-24\end{array}$ & $\begin{array}{r}-7 \\
-18 \\
-14\end{array}$ \\
\hline Low $\mathrm{NaCl}$ intake & $\begin{array}{l}\mathrm{B} \\
\mathrm{F} \\
\mathrm{H}\end{array}$ & $\begin{array}{r}-39 \\
+\quad 1 \\
+10\end{array}$ & $\begin{array}{l}+27 \\
+25 \\
+36\end{array}$ \\
\hline
\end{tabular}

$* 2.7 \mathrm{mEq}$ potassium/g nitrogen.

simply for expansion of extracellular fluid with a constant chloride-sodium ratio, and the values for excess chloride are similar to those for the highsalt dogs (Table I). It was of interest that the figures for corrected chloride losses during the $\mathrm{CO}_{2}$ period (3) were of the same order of magnitude.

The cumulative $\Delta$ potassium balance in the highand low-salt dogs during the period of exposure to $\mathrm{CO}_{2}$ is shown in Table II. Since there were no important gains or losses of potassium in the control period (3), the figures in this table can be taken to indicate the state of potassium balance of the dogs at the beginning of the recovery phase. The serum potassium concentration in the highsalt dogs during the recovery period ranged from 3.2 to $4.7 \mathrm{mEq}$ per $\mathrm{L}$, a range not significantly different from that observed during the $\mathrm{CO}_{2}$ period. In the low-salt dogs, the serum potassium concentration ranged from 3.3 to $4.0 \mathrm{mEq}$ per L, values which on the average were slightly lower than those during the control and $\mathrm{CO}_{2}$ periods. With the addition of sodium chloride to the diet there was little, if any, significant change in serum potassium concentration. The final values ranged between 3.6 and $4.4 \mathrm{mEq}$ per $\mathrm{L}$.

On the first day in room air all of the high-salt dogs and two of the three low-salt dogs retained potassium, in amounts ranging from 10 to $25 \mathrm{mEq}$. Subsequently, there were only slight fluctuations in $\Delta$ potassium balance, and these can be accounted for by correction for nitrogen balance. Cumulative $\Delta$ potassium balance (Table I) in the highsalt group, and in the low-salt group before adding salt, was small and variable. When salt was 


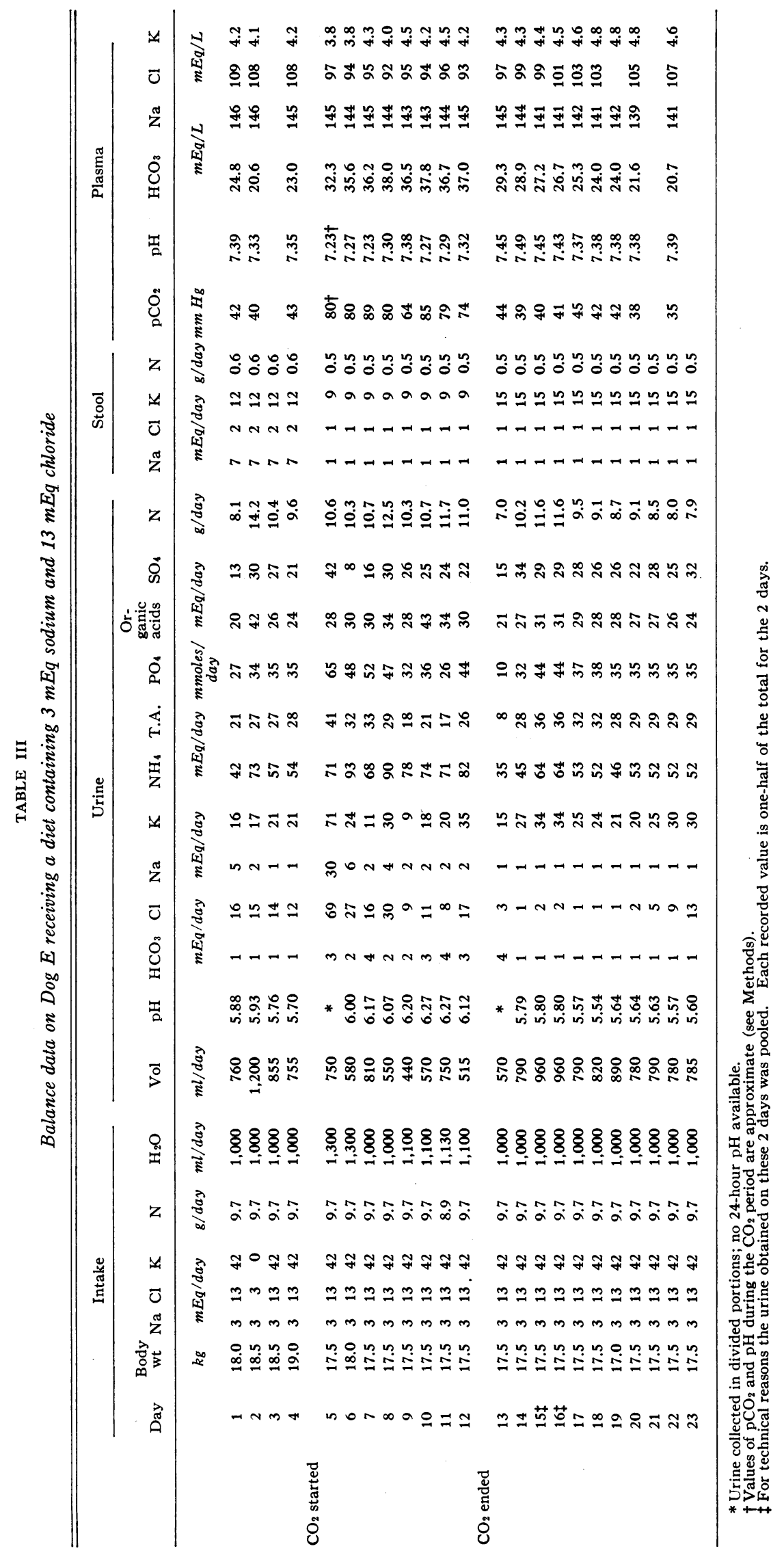




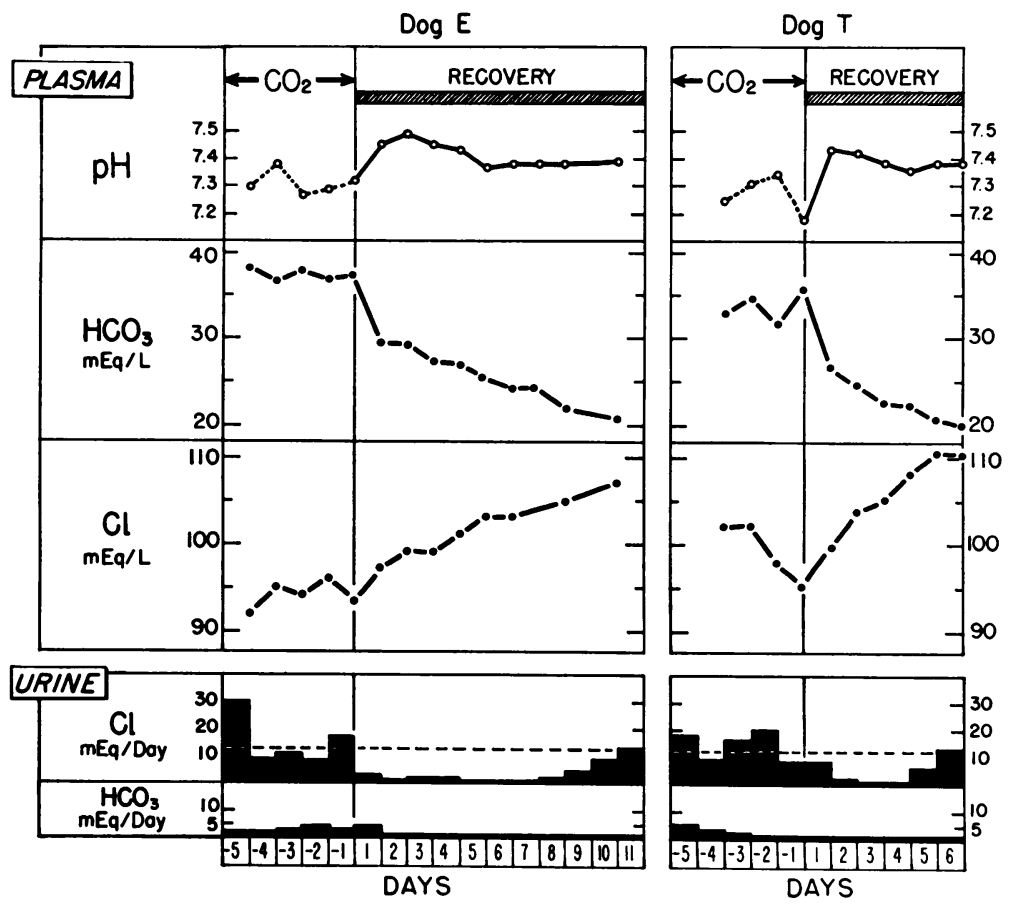

Fig. 5. Recovery studies in two dogs Receiving a diet CONTAINING 3 MEQ of sodium ANd $13 \mathrm{MEQ}_{\mathrm{Q}}$ of Chloride. Days -1 to -5 refer to the last 5 days of exposure to a high $\mathrm{CO}_{2}$ atmosphere. The values for $\mathrm{pH}$ during exposure to $\mathrm{CO}_{2}$ are shown with a dashed line since they are only approximate (3). The dashed line represents the daily intake of chloride.

added to the diet of the low-salt group, $\Delta$ potassium balance became significantly positive in two of the three dogs; but, corrected for nitrogen, there was no significant retention (Table I).

3 Nitrogen, phosphorus, organic acids, and sulfate. In the high-salt group, the negative $\Delta$ nitrogen balance of the $\mathrm{CO}_{2}$ period continued for the first 2 days of the recovery period and then gradually became less negative, until all the dogs were virtually at control levels. In the three lowsalt dogs, $\Delta$ nitrogen balance remained the same as it had been during the latter part of the $\mathrm{CO}_{2}$ period. However, when salt was added to the diet, there was a striking and persistent retention of nitrogen (Table I).

During the first day of recovery, urinary phosphate fell sharply in both high- and low-salt groups, to values 6 to 20 mmoles below the control level. In both the high- and low-salt groups, phosphorus excretion returned to the control range by the second or third day. When the lowsalt diet was supplemented with salt, urinary phosphate was again suppressed in two of the three dogs (about 10 mmoles per day) and this suppression persisted. The reduction in phosphate excretion correlated closely with the degree of nitrogen retention.

During the recovery period sulfate and organic acid excretion generally remained within \pm 10 $\mathrm{mEq}$ of the control values. As in the previous periods, sulfate and organic acid excretion tended to parallel nitrogen excretion.

4. Miscellaneous data. There was no significant change in the weight of either the high- or lowsalt group after removal from the $\mathrm{CO}_{2}$ atmosphere, but when salt was added to the diet of the low-salt group, each dog gained approximately $0.5 \mathrm{~kg}$. Hematocrit was measured in four dogs at the end of the study and ranged from 39 to 45 per cent.

Stool content of sodium and chloride did not change significantly in either group during the recovery period, the figure for sodium averaging approximately 4 , and that for chloricle approximately $1 \mathrm{mEq}$ per day. In the high-salt group the fecal potassium was unchanged from the previ- 
ous periods, averaging $1 \mathrm{mEq}$ per day. Data for stool composition before and after addition of salt to the diet are available for two low-salt dogs. In these, fecal potassium, which had been approximately $6 \mathrm{mEq}$ per day (in $\mathrm{CO}_{2}$ ), rose during the recovery period to 10 and $15 \mathrm{mEq}$ per day, respectively. When salt was added to the diet, they both showed a fall in fecal potassium to less than $3 \mathrm{mEq}$ per day.

\section{B. Studies of two dogs receiving a diet containing $3 \mathrm{mEq}$ of sodium and $13 \mathrm{mEq}$ of chloride}

Balance data on Dog E, receiving a diet containing $3 \mathrm{mEq}$ of sodium and $13 \mathrm{mEq}$ of chloride, are shown in Table III and Figure 5. One day after the end of the $\mathrm{CO}_{2}$ period (Day 13) the arterial $\mathrm{pCO}_{2}$ was $44 \mathrm{~mm} \mathrm{Hg}$ and remained between 38 and 45 for the rest of the study. Plasma bicarbonate, which was $37.0 \mathrm{mEq}$ per $\mathrm{L}$ at the close of the $\mathrm{CO}_{2}$ period, fell $7.7 \mathrm{mEq}$ during the first day of recovery (Day 13 ) to $29.3 \mathrm{mEq}$ per $\mathrm{L}$, a level of $6.3 \mathrm{mEq}$ above the final control figure. This fall was accompanied by a rise in plasma $\mathrm{pH}$ to 7.45 , a value significantly above the control range. Bicarbonate excretion was negligible $(4 \mathrm{mEq})$ and was unchanged from the values seen during exposure to $\mathrm{CO}_{2}$. Net acid excretion fell to a value $42 \mathrm{mEq}$ below the mean control level and $56 \mathrm{mEq}$ below the mean value for the last 2 days in $\mathrm{CO}_{2}$. This reduction was due to a fall in the excretion of both ammonium and titratable acid.

During the rest of the recovery period (Days 14 through 23), the plasma bicarbonate and $\mathrm{pH}$ descended gradually to the control range. Over this interval the urine was virtually free of bicarbonate $(1 \mathrm{mEq}$ per day). Net acid excretion returned approximately to the control level by the third day.

The gradual descent of the plasma bicarbonate to control levels during the recovery period was accompanied by a gradual ascent of the plasma chloride to its control level (Figure 5). The correction of the hypochloremia was associated during the first 8 recovery days (13 through 20) with a consistently positive chloride balance averaging $10 \mathrm{mEq}$ per day, the urine remaining virtually chloride-free. During the remaining 3 days (21 through 23 ), as the plasma chloride and bicarbonate returned almost simultaneously to their control levels, the urinary chloride output also returned to its control level, which approximated the intake of $13 \mathrm{mEq}$ per day. The cumulative $\Delta$ chloride balance, which during the 8-day $\mathrm{CO}_{2}$ period had been $-83 \mathrm{mEq}$, was $+103 \mathrm{mEq}$ during the 11-day recovery period. The urine stayed virtually sodium-free during recovery, but since the diet contained only $3 \mathrm{mEq}$ per day, there was no significant sodium retention.

The cumulative $\Delta$ potassium balance in the $\mathrm{CO}_{2}$ period was $+40 \mathrm{mEq}$ and, corrected for nitrogen, $+53 \mathrm{mEq}$. Since the dog was in potassium balance in the control period, these figures can be taken to indicate that it was in positive balance at the beginning of recovery. The urinary potassium output fell on the first recovery day (Day 13), giving rise to a $\Delta$ balance of $+11 \mathrm{mEq}$. Subsequently, the dog remained approximately in potassium balance. The plasma potassium, which had been normal during the previous part of the study, remained so during recovery. Table III shows that the phosphate excretion, like potassium excretion, was markedly reduced on the first day of the recovery period. Subsequently, it returned to control values. The hematocrit ranged from 41 to 46 per cent and the weight remained constant.

In the right-hand section of Figure 5, data are presented on a second $\operatorname{dog}(\mathrm{T})$ receiving a chloride supplement. Full correction of the hypochloremic alkalosis was achieved in 5 to 6 days, during which time the net retention of chloride was $32 \mathrm{mEq}$. As before, after serum chloride had risen to normal, urinary chloride output also rose to a level which approximated the chloride intake. As would be expected on a low-sodium intake, the urine remained virtually sodium-free throughout recovery; sodium balance was essentially zero. The potassium balance during recovery was $-29 \mathrm{mEq}$, or $-20 \mathrm{mEq}$ after correction for nitrogen balance. Net acid excretion showed little change on the first day in room air but fell significantly during the 3 subsequent days.

\section{DISCUSSION}

It has been previously demonstrated that adaptation to chronic respiratory acidosis is uninfluenced by the salt content of the diet, the same rise in plasma bicarbonate concentration and fall in 
plasma chloride occurring regardless of the presence or absence of sodium chloride (3). By contrast, the present data indicate that the electrolyte intake exerts a marked influence on the recovery process, restriction of salt impeding the full restoration of normal acid-base and electrolyte equilibrium. In animals on a high-salt intake, withdrawal from $\mathrm{CO}_{2}$ was followed by a prompt fall in bicarbonate concentration to control levels of 21 to $24 \mathrm{mEq}$ per $\mathrm{L}$. On the other hand, in sodium chloride-restricted animals the bicarbonate concentration fell significantly less, and remained in the range of 27 to $30 \mathrm{mEq}$ per L, with the result that blood $\mathrm{pH}$ rose above normal. This abnormal state persisted throughout the 5- to 6-day period of observation. That a restricted salt intake was a critical factor in maintaining the elevation of plasma bicarbonate was evidenced by the prompt fall to the normal range that followed addition of sodium chloride.

The alterations in plasma bicarbonate were associated with characteristic and virtually reciprocal changes in plasma chloride concentration. ${ }^{2}$ Thus, in the high-salt group the chloride concentration promptly returned to normal, while in the low-salt group hypochloremia persisted until the addition of salt.

While these studies indicate that salt intake played an important role in the restoration of the normal electrolyte composition and $\mathrm{pH}$ of the extracellular fluid, they permit no conclusion as to whether it was the sodium ion, the chloride ion, or both, which were responsible. However, two additional studies (Figure 5 and Table III) of dogs on a diet low in sodium, but containing 13 $\mathrm{mEq}$ of chloride per day, demonstrated that provision of chloride alone is sufficient to permit full correction of the acid-base disturbance. In these two experiments, despite the almost complete absence of sodium from the diet, plasma bicarbonate

\footnotetext{
${ }^{2}$ It should be noted, however, that on the first day in room air the fall in bicarbonate in both groups exceeded the rise in serum chloride, and there was an increase of approximately 4 to $6 \mathrm{mEq}$ per $\mathrm{L}$ in the concentration of "unmeasured anions." This discrepancy disappeared quickly in the high-salt dogs, but persisted in the lowsalt group until the addition of sodium chloride. No measurements were made of lactate or pyruvate levels, but increments in the concentration of both are known to occur during metabolic alkalosis (4), and may have accounted, at least in part, for the increase in unmeasured anions during the period that blood $\mathrm{pH}$ was elevated.
}

concentration fell gradually to normal levels in 5 to 7 days after withdrawal from $\mathrm{CO}_{2}$, while there was a reciprocal rise in serum chloride concentration. The urine remained virtually chloridefree until the serum chloride concentration had reached a normal level, and chloride excretion then rose promptly to values equal to the intake.

It is noteworthy that the fall in plasma bicarbonate, when the dogs were returned to room air, usually occurred without a significant bicarbonate diuresis. It might reasonably have been anticipated that, with a sudden fall in $\mathrm{pCO}_{2}$, bicarbonate excretion would have increased as it does when a comparable disproportion between $\mathrm{pCO}_{2}$ and plasma bicarbonate is created by hyperventilation (5). There is no obvious explanation for this difference in response, but it is conceivable that increased avidity for sodium accounted for the absence of a bicarbonate diuresis. It is well known, for example, that severe salt depletion prevents the alkalinization of the urine which normally occurs in response to respiratory (6) and metabolic $(7,8)$ alkalosis. On the other hand, mild sodium depletion of a degree similar to that which may have existed in the present study does not prevent alkalinization of the urine with hyperventilation (5). Furthermore, the dogs in the low-salt group did not have a bicarbonate diuresis even when given salt, an observation which stands in contrast to those of Gamble and Ross (7) and Van Slyke and Evans (8), who demonstrated a prompt bicarbonate diuresis when sodium chloride was administered to salt-depleted alkalotic animals. Finally, it should be noted that the high-salt dogs continued to excrete significant quantities of sodium and chloride during the period of correction, even at a time when they were in positive sodium balance. Thus, from the available evidence, it seems unlikely that sodium depletion was responsible for the failure to excrete bicarbonate in either group. The explanation of this phenomenon remains obscure.

There is no evidence for a significant difference in body potassium stores between the highand low-salt dogs to account for the higher plasma bicarbonate concentration that was maintained by the low-salt animals. At the end of the $\mathrm{CO}_{2}$ period, little or no potassium deficiency was present in either group. Although slight potassium re- 
tention occurred on the first day in room air in both groups, in neither was there a significant cumulative loss or retention. Such retention of potassium as occurred when salt was added to the low-salt diet was no more than would be expected in association with the marked nitrogen retention which occurred simultaneously.

In the absence of a bicarbonate diuresis, it is obvious that the fall in plasma bicarbonate level must be accounted for either by a redistribution of hydrogen within the body, or by a reduction in renal acid excretion. It is likely that the reduction of the $\mathrm{pCO}_{2}$ to normal was accompanied by a migration of hydrogen ions from cells to the extracellular fluid, analogous to that which occurs in acute respiratory alkalosis (9). Such a migration could account for the substantial but incomplete reduction in plasma bicarbonate that occurred initially in all three low-salt dogs, two of which had no significant suppression of renal acid excretion. A similar contribution of tissue hydrogen would also explain half, or more, of the reduction in bicarbonate concentration in the dogs receiving salt, and it seems probable that the transient suppression of renal acid excretion that occurred consistently in this latter group accounted for the remainder of the fall to the control level. This view is supported by the further observation that the decrement of plasma bicarbonate following addition of salt to the diet of the low-salt group was also accompanied by a striking suppression of acid excretion. It should be emphasized, however, that the above interpretations of changes in acid excretion rest on the assumption that the endogenous (metabolic) acid load remains constant. The limitations and possible errors in this assumption have been considered previously (3).

Regardless of the mechanism responsible for the smaller initial fall in plasma bicarbonate concentration in the low-salt dogs, it is evident that the kidney was responsible for the sustained elevation of plasma bicarbonate concentration during the subsequent week of observation. If, as is currently believed, bicarbonate reabsorption takes place entirely by means of hydrogen ion secretion, it can be concluded that the transfer of hydrogen into the glomerular filtrate continued at a markedly elevated rate in the low-salt dogs during the recovery phase. Why it is that chloride deficiency sustains an increased reabsorption of bicarbonate, even when plasma $\mathrm{CO}_{2}$ tension is normal, is not clear from the present data. However, it is conceivable that when the concentration of chloride in the glomerular filtrate is low, so that less chloride is available to reduce the potential set up by active transport of sodium, a counter-diffusion of hydrogen ions into the tubular lumen is induced. Such an enhancement of hydrogen transfer would explain the complete reabsorption of the increased bicarbonate load and the maintenance of a normal rate of titratable acid and ammonium excretion in the face of an extracellular alkalosis. As chloride is added to the diet, and as more chloride is thus made available for reabsorption, the rate of hydrogen diffusion would be expected to fall. Consequently, the removal of bicarbonate from the filtrate would presumably be completed at a more distal site in the tubule, and the rate of acid excretion would diminish. This hypothesis is consistent with previous experiments showing that the rate of acid excretion can be markedly increased in the nonacidotic dog when the availability of chloride is severely limited. In these experiments the infusion of phosphate induced near-maximal excretion of titratable acid, and the subsequent administration of chloride was followed by marked suppression of acid excretion (10). It should be emphasized, however, that the present experimental conditions are very different and, in any event, the hypothesis concerning the influence of chloride on the process of recovery from chronic respiratory acidosis must be regarded as highly speculative and in need of further investigation.

\section{SUM MARY}

Balance studies have been carried out in eight dogs during recovery from chronic respiratory acidosis induced by a high $\mathrm{CO}_{2}$ atmosphere. Four animals had received a high-salt diet and four others a low-salt diet during the period of exposure to $\mathrm{CO}_{2}$, and each group was maintained on the same diet throughout the recovery period. At the end of the $\mathrm{CO}_{2}$ period, plasma bicarbonate concentration ranged from 35 to $38 \mathrm{mEq}$ per $\mathrm{L}$ in both groups; plasma chloride concentration was depressed. After being returned to room air, the high-salt dogs showed a prompt reduction in plasma bicarbonate concentration to a normal range of 21 to $24 \mathrm{mEq}$ per $\mathrm{L}$, and the plasma chloride concentration rose simultaneously to a nor- 
mal level. By contrast, the low-salt dogs had a significantly smaller reduction in plasma bicarbonate concentration, to values of approximately 27 to $30 \mathrm{mEq}$ per $\mathrm{L}$, and became mildly alkalotic; plasma chloride concentration showed little or no change. The fall in plasma bicarbonate in both groups usually took place without loss of bicarbonate in the urine.

During the subsequent 6 days the low-salt dogs stabilized their plasma bicarbonate levels in a range consistently above the normal; the plasma chloride concentration in these animals remained grossly subnormal. The persistent elevation of plasma bicarbonate concentration in the low-salt animals indicates that an elevated rate of hydrogen ion secretion persisted despite a normal plasma carbon dioxide tension. Potassium deficiency did not appear to be a factor in the difference observed between the low- and high-salt groups.

When salt was added to the diet of the low-salt dogs, the plasma bicarbonate fell to normal, and there was a reciprocal rise in plasma chloride concentration. The reduction in bicarbonate was achieved without urinary bicarbonate loss but was associated with a marked suppression of acid excretion. Two additional studies of animals given a diet low in sodium but containing a moderate amount of chloride demonstrated that the acidbase disturbance and hypochloremia could be corrected solely by the provision of chloride.

A possible mechanism to account for the observed effect of chloride deficiency in impeding the restoration of normal acil-base balance has been considered.

\section{REFERENCES}

1. Levitin, H., Branscome, W., and Epstein, F. H. The pathogenesis of hypochloremia in respiratory acidosis. J. clin. Invest. 1958, 37, 1667.

2. Carter, N. W., Seldin, D. W., and Teng, H. C. Tissue and renal response to chronic respiratory acidosis. J. clin. Invest. 1959, 38, 949.

3. Polak, A., Haynie, G. D., Hays, R. M., and Schwartz, W. B. Effects of chronic hypercapnia on electrolyte and acid-base equilibrium. I. Adaptation. J. clin. Invest. 1961, 40, 1223.

4. Huckabee, W. E. Relationships of pyruvate and lactate during anaerobic metabolism. I. Effects of infusion of pyruvate or glucose and of hyperventilation. J. clin. Invest. 1958, 37, 244.

5. Stanbury, S. W., and Thompson, A. E. The renal response to respiratory alkalosis. Clin. Sci. 1952, $11,357$.

6. McCance, R. A., and Widdowson, E. M. The response of the kidney to an alkalosis during salt deficiency. Proc. Roy. Soc. B 1936, 120, 228.

7. Gamble, J. L., and Ross, S. G. The factors in the dehydration following pyloric obstruction. J. clin. Invest. 1924-25, 1, 403.

8. Van Slyke, K. K., and Evans, E. I. The paradox of aciduria in the presence of alkalosis caused by hypochloremia. Ann. Surg. 1947, 126, 545.

9. Giebisch, G., Berger, L., and Pitts, R. F. The extrarenal response to acute acid-base disturbances of respiratory origin. J. clin. Invest. 1955, 34, 231.

10. Bank, N., and Schwartz, W. B. The influence of anion penetrating ability on urinary acidification and the excretion of titratable acid. J. clin. Invest. $1960,39,1516$. 